\title{
Correction to: A Digital Adaptive Calibration Method of Timing Mismatch in TIADC Based on Adjacent Channels Lagrange Mean Value Difference
}

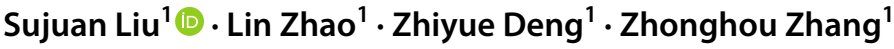

Published online: 19 August 2021

(C) The Author(s), under exclusive licence to Springer Science+Business Media, LLC, part of Springer Nature 2021

\section{Correction to: Circuits, Systems, and Signal Processing https://doi.org/10.1007/s00034-021-01785-8}

In this article, Eq. (22) was incorrectly given and should have read as below,

$$
\hat{x}_{(2)}[n]=y[n]-\Delta t_{i}\left[y[n]-\Delta t_{i} y^{\prime}[n]\right]^{\prime}-\frac{1}{2} \Delta t_{i}^{2} y^{\prime \prime}[n] .
$$

Publisher's Note Springer Nature remains neutral with regard to jurisdictional claims in published maps and institutional affiliations.

The original article can be found online at https://doi.org/10.1007/s00034-021-01785-8.

Sujuan Liu

liusujuan@bjut.edu.cn

Lin Zhao

zhaolin@emails.bjut.edu.cn

Zhiyue Deng

dddzy425@163.com

Zhonghou Zhang

zzhkobe@emails.bjut.edu.cn

1 College of Microelectronics, Beijing University of Technology, Beijing, China 